\title{
A EDUCAÇÃO BÁSICA NO BRASIL
}

\author{
Carlos Roberto Jamil Cury
}

RESUMO: A educação básica no Brasil, desde a Constituição de 1988 e, com mais ênfase, nos últimos oito anos, vem sofrendo grandes mudanças. Analisá-la implica considerar determinadas preliminares como o pacto federativo, a desigualdade social, as ligações internacionais e a própria noção de educação básica a fim de contextualizar as políticas de avaliação, focalização, descentralização, desregulamentação e financiamento. Tais alterações evidenciam uma forte focalização no ensino fundamental na idade legal apropriada, o mesmo não acontecendo com as outras etapas tão importantes quanto o ensino fundamental.

Palavras-chave: Política educacional. Educação básica. Política educacional e educação básica. Estado e educação.

\section{BASIC EDUCATION IN BRAZIL}

ABSTRACT: Since the 1988 Constitution, and more specifically during the 8 last years, basic education in Brazil has undergone great changes. Analyzing it implies considering such given preliminaries as the federative pact, social inequities, the international links and the very notion of basic education so that the assessment, focalization, decentralization, deregulation and financing policies can be contextualized. These changes manifest a strong focalization on primary education at legal age. Such is not the case with other steps, as important as primary education.

Key words: Educational policies. Basic education. Educational policies and basic education. State and education.

Professor da Pontifícia Universidade Católica de Minas Gerais (PUC-MG) e membro do CNE.E-mail: crjcury.bh@terra.com.br 
educação básica no Brasil ganhou contornos bastante complexos nos anos posteriores à Constituição Federal de 1988

e, sobretudo, nos últimos oito anos. Analisá-la não é fácil exatamente porque as contingências que a cercam são múltiplas e os fatores que a determinam têm sido objeto de leis, políticas e programas nacionais, alguns dos quais em convênio com órgãos internacionais.

Assim, um cuidado para efeito de análise é separar os fatores condicionantes (quando possível) para se ter uma visão mais contextualizada da situação. Neste ensaio consideraremos quatro preliminares importantes nesse cuidado de análise.

A primeira preliminar é não ignorar o que é a situação do Brasil em matéria socioeconômica. De há muito os educadores brasileiros correlacionam dialeticamente sociedade e educação. Sabemos todos que a distribuição de renda e da riqueza no país determina o acesso e a permanência dos estudantes na escola. Sabemos também que o aumento da permanência de estudantes na escola depende da realização do direito ao saber, sob um padrão de qualidade possível de ser incrementado. E sabemos também que não se deve exigir da escola o que não é dela, superando a concepção de uma educação salvífica e redentora. Problemas há na escola que não são dela, mas que estão nela e problemas há que são dela e obviamente podem também estar nela. Considerar este contexto socioecônomico descritiva e analiticamente, vê-lo como suscetível de superação por meio de políticas sociais redistributivas e considerar a situação da educação escolar enquanto tal são princípios metodológicos indispensáveis para uma análise adequada das políticas educacionais. Afirmar a determinação socioeconômica sobre a educação não é negar as determinações internas a ela.

A segunda preliminar a ser analisada é o próprio conceito de educação básica. Trata-se de um novo conceito, avançado, pelo qual o olhar sobre a educação ganha uma nova significação.

A Constituição Federal de 1988, no capítulo próprio da educação, criou as condiçôes para que a Lei de Diretrizes e Bases da Educação Nacional, Lei no 9.394/96, assumisse esse conceito

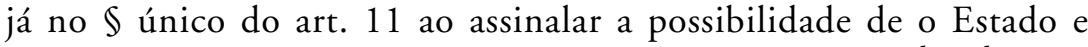
os municípios se constituírem como um sistema único de educação básica. Mas a educação básica é um conceito, definido no art. 21 como um nível da educação nacional e que congrega, articuladamente, as três etapas que estão sob esse conceito: a educação infan- 
til, o ensino fundamental e o ensino médio. E o art. 22 estabelece os fins da educação básica:

A educação básica tem por finalidade desenvolver o educando, assegurarlhe a formação comum indispensável para o exercício da cidadania e fornecer-lhe meios para progredir no trabalho e em estudos posteriores.

Trata-se, pois, de um conceito novo, original e amplo em nossa legislação educacional, fruto de muita luta e de muito esforço por parte de educadores que se esmeraram para que determinados anseios se formalizassem em lei. A idéia de desenvolvimento do educando nestas etapas que formam um conjunto orgânico e seqüencial é o do reconhecimento da importância da educação escolar para os diferentes momentos destas fases da vida e da sua intencionalidade maior já posta no art. 205 da Constituição Federal:

A educação, direito de todos e dever do Estado e da família, será promovida e incentivada com a colaboração da sociedade, visando ao pleno desenvolvimento da pessoa, seu preparo para o exercício da cidadania e sua qualificação para o trabalho.

Mas o art. 22 da LDB, a fim de evitar uma interpretação dualista entre cidadania e trabalho e para evitar o tradicional caminho no Brasil de tomar a qualificação do trabalho como uma sala sem janelas que não a do mercado, acrescenta como próprios de uma educação cidadã tanto o trabalho quanto o prosseguimento em estudos posteriores.

A própria etimologia do termo base nos confirma esta acepção de conceito e etapas conjugadas sob um só todo. Base provém do grego básis, eós e significa, ao mesmo tempo, pedestal, suporte, fundação e andar, pôr em marcha, avançar. A educação básica é um conceito mais do que inovador para um país que, por séculos, negou, de modo elitista e seletivo, a seus cidadãos o direito ao conhecimento pela ação sistemática da organização escolar.

Resulta daí que a educação infantil é a base da educação básica, o ensino fundamental é o seu tronco e o ensino médio é seu acabamento, e é de uma visão do todo como base que se pode ter uma visão conseqüente das partes.

A educação básica torna-se, dentro do art. $4^{\circ}$ da LDB, um direito do cidadão à educação e um dever do Estado em atendê-lo mediante oferta qualificada. E tal o é por ser indispensável, como 
direito social, a participação ativa e crítica do sujeito, dos grupos a que ele pertença, na definição de uma sociedade justa e democrática.

Uma terceira preliminar resulta, então, da mola insubstituível que põe em marcha este direito a uma educação básica: a ação responsável do Estado e suas obrigações correspondentes. Sendo um serviço público (e não uma mercadoria) da cidadania, a nossa Constituição reconhece a educação como direito social e dever do Estado. Mesmo quando autorizada pelo Estado a oferecer esse serviço, a instituição privada não deixa de mediar o caráter público inerente à educação. Só que esta ação obrigatória do Estado vai se pôr em marcha no interior de um Estado federativo.

O Brasil é um país federativo. E um país federativo supõe o compartilhamento do poder e a autonomia relativa das circunscrições federadas em competências próprias de suas iniciativas. Outra suposição de uma organização federativa, decorrente da anterior, é a não-centralização do poder. Isso significa a necessidade de um certo grau de unidade e sem amordaçar a diversidade. E, na forma federativa adotada pela $\mathrm{CF} / 88$, com 27 estados e mais de 5.500 municípios, só a realização do sistema federativo por cooperação recíproca, constitucionalmente previsto, poderá encontrar os caminhos para superar os entraves e os problemas que atingem nosso país.

A Constituição Federal de 1988 reconhece o Brasil como uma República Federativa formada pela união indissolúvel dos estados e

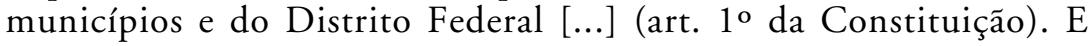
ao se estruturar assim o faz sob o princípio da cooperação, de acordo com os artigos $1^{\circ}, 18,23$ e $60, \$ 4^{\circ}$, I.

Para dar conta deste modelo federado e cooperativo, a Constituição compôs um ordenamento jurídico complexo no qual coexistem, segundo Almeida (1991, p. 79), competências privativas, repartidas horizontalmente, com competências concorrentes, repartidas verticalmente, abrindo-se espaço também para a participação das ordens parciais na esfera de competências próprias da ordem central, mediante delegação. Junto com estas, associam-se as competências comuns.

As competências privativas da União estão previstas, sobretudo, nos art. 21 e 22.

As competências privativas dos estados estão listadas no art. $18, \$ 4^{\circ}$, e nas competências residuais não enumeradas no art. 25 e as listadas nos $\$ \$ 2^{\circ}$ e $3^{\circ}$ do mesmo art. 25; as competências privativas dos municípios são listadas no art. 30. Ele contém matéria 
própria dos municípios, mas que também não deixa de fazer interface com os estados, o Distrito Federal e a União.

$\mathrm{O}$ art. 23 lista as competências comuns cuja efetivação se impõe como tarefa de todos os entes federativos, pois as finalidades nelas postas são de tal ordem que, sem o concurso de todos eles, elas não se realizariam. Deve-se assinalar o inciso V que diz ser competência comum proporcionar os meios de acesso à cultura, à educação e à ciência.

É importante assinalar o que diz o $\$$ único desse art. 23: "Lei complementar fixará normas para a cooperação entre a União e os Estados, o Distrito Federal e os Municípios, tendo em vista o equilíbrio do desenvolvimento e do bem-estar em âmbito nacional".

No art. 24 figuram as competências concorrentes entre União, estados e Distrito Federal. É preciso observar que, nesse caso, são assuntos sobre os quais estes entes federativos podem legislar. O inciso IX diz ser matéria concorrente de todos educação, cultura, ensino e desporto.

A delegação de competências, por sua vez, está no art. 22, $\$$ único, que diz: "Lei complementar poderá autorizar os estados a legislar sobre questôes específicas das matérias relacionadas neste artigo".

Percebe-se, pois, que ao invés de um sistema hierárquico ou dualista, comumente centralizado, a Constituição federal montou um sistema de repartição de competências e atribuições legislativas entre os integrantes do sistema federativo, dentro de limites expressos, reconhecendo a dignidade e a autonomia próprias destes como poderes públicos.

A Constituição fez escolha por um regime normativo e político, plural e descentralizado no qual se cruzam novos mecanismos de participação social com um modelo institucional cooperativo e recíproco que amplia o número de sujeitos políticos capazes de tomar decisões. Por isso mesmo a cooperação exige entendimento mútuo entre os entes federativos e a participação supõe a abertura de arenas públicas de decisão.

O modelo de distribuição de competências objetiva conjugar as atribuições repartindo-as cooperativamente e, quando for o caso, impondo casos de limitação tais como os expostos no art. 34. Buscase pois uma finalidade comum, um sentido geral, com regras e normas de modo que se obtenha uma harmonia interna. Mas todas essas competências e limitações encontram seu fundamento de validade na mesma fonte, isto é, na Constituição federal. 
Espera-se, com isso, que não haja antinomias no interior das e entre as competências e que, coexistindo lado a lado, formem um conjunto harmonioso visando a fundamentos, objetivos e finalidades maiores e comuns postos na Constituição.

Mas, a Constituição, ao invés de criar um sistema nacional de educação, como o faz com o sistema financeiro nacional, com o sistema nacional de emprego ou como o faz com o sistema único de saúde, opta por pluralizar os sistemas de ensino (art. 211) cuja articulação mútua será organizada por meio de uma engenharia consociativa de e articulada com normas e finalidades gerais, por meio de competências privativas, concorrentes e comuns. A insistência na cooperação, a divisão de atribuiçôes, a assinalação de objetivos comuns com normas nacionais gerais indicam que, nesta Constituição, a acepção de sistema dá-se como sistema federativo por colaboração tanto quanto de Estado Democrático de Direito.

A Lei de Diretrizes e Bases da Educação Nacional denominará tal pluralidade consociativa de Sistema de Organização da Educação Nacional, em seu Título IV. É desta concepção articulada entre os sistemas que decorre a exigência de um Plano Nacional de Educação (art. 214 da Constituição Federal) que seja, ao mesmo tempo, racional nas metas e nos meios, e efetivo nos seus fins.

Tal concepção oposta à nossa tradição centralizadora e ao caráter vertical das decisões dos poderes executivos não é de fácil implementação. A pergunta aqui é direta: "quem (re)educará o educador"?

Um dos obstáculos para a realização deste modelo federado é a desproporção existente entre os estados do Brasil seja sob o ponto de vista de recursos financeiros, seja do ponto de vista de presença política, seja do ponto de vista de tamanho, demografia e recursos naturais.

Um outro óbice importante, até agora, para efeito de um sistema articulado nos fins e cooperativo nos meios e nas competências é a ausência de uma definição do que vem a ser o regime de colaboração, como determina o $\$$ único do art. 23 da Constituição Federal. O Congresso, até a presente data, não regulamentou ainda este aspecto nuclear do pacto federativo. Trata-se de matéria da mais alta importância e significado para o conjunto das ações públicas e, em especial, para a manutenção e desenvolvimento do ensino. A feitura desta lei complementar possibilitaria o aprimoramento na sistematização das competências a fim de coordená-las de modo claro 
na forma, cooperativo na articulação e eficaz no desenvolvimento e bemestar dos cidadãos brasileiros. $\mathrm{Na}$ ausência de uma tal definição e que dela decorresse um sistema de constrangimentos legais, o risco que se corre é de transformar a cooperação em competição, como no caso da chamada "guerra fiscal". $\mathrm{Na}$ sua ausência, pode-se aventar a hipótese de uma continuidade de traços pré-1988, sobretudo na repartição e distribuição de impostos em face das novas competências e da entrada de novos condicionantes provindos da descentralização entendida sob a crítica a uma postura estatal burocratizada e pouco flexível.

Com esta ausência, a Lei de Responsabilidade Fiscal, em que pesem seus pontos positivos, corre o risco de manter as atuais disparidades entre os municípios e estados.

Nesse caso, não se pode negar o papel determinante da União no estabelecimento de políticas públicas e, no caso, de políticas educacionais. É o caso específico do FUNDEF, que alterou significativamente os padróes de oferta e de atendimento dos governos subnacionais, no que se refere ao conjunto da educação básica, ao focalizar apenas o ensino fundamental.

Aprovadas as diretrizes e bases da educação nacional, via Lei no 9.394/96, o governo federal, disposto a aplicar o regime descentralizado (o qual em matéria de educação escolar provém de 1834) sob o enfoque da focalização, obteve êxito incomum na aprovação da Emenda no 14/96, e da qual resultou a aprovação da Lei $n^{\circ}$ $9.424 / 96$, quase que concomitante à aprovação da LDB. Esta legislação reforça a política histórica de descentralização de atribuições e recursos, com controle recentralizado na União.

O FUNDEF, ora vigente, impõe a consideração de alguns pontos a serem analisados: a manutenção de vínculos orçamentários constitucionais, a subvinculação obrigatória de recursos ante os entes federativos, a criação de Conselhos Civis com incumbências fiscais e de controle, a presença ativa dos Tribunais de Contas, o cumprimento exato das disposiçóes legais e questôes federativas pendentes.

$\mathrm{O}$ primeiro ponto representa a manutenção de uma conquista importante para uma política social voltada para a educação, um verdadeiro amortecedor de impactos quando as palavras de ordem são a retirada do Estado, o recuo deste das políticas públicas e a interface do Estado com órgãos internacionais. A nova LDB instaurou o conceito de educação básica como direito da cidadania e dever do Estado cobrindo três etapas seqüenciais da escolarização: a educação 
infantil, o ensino fundamental e o ensino médio. E os recursos vinculados devem ser voltados para a manutenção e o desenvolvimento da educação.

A contrapartida deste ponto é a focalização da política educacional no ensino fundamental gratuito, obrigatório, presencial, na faixa etária de 7 a 14 anos. Como se sabe a focalização é um modo de priorizar uma etapa do ensino cujo foco pode significar o recuo ou o amortecimento ou o retardamento quanto à universalização de outras etapas da educação básica e a sua sustentação por meio de recursos suficientes.

O segundo ponto representa um imperativo de suma importância a fim de que os municípios (muitos dos quais não priorizavam o ensino fundamental) sejam obrigados a investir no ensino fundamental. Com efeito, o FUNDEF foi o modelo encontrado para que a manutenção e o desenvolvimento do ensino fundamental fosse o foco das políticas com envolvimento das três esferas federadas, com a prioridade dessa etapa atribuída aos municípios. Trata-se de uma decisão planejada do poder público federal, intencionalmente dirigida, e talvez seja a única política a apresentar resultados positivos. Municípios que jamais haviam investido em educação fundamental, sob pena de perdas de recursos, viram-se obrigados a repensar suas políticas para o setor. É preciso reconhecer que a inspiração cooperativa dos três níveis de poder provém de iniciativas e propostas postas por Anísio Teixeira na década de 1950. Um problema crucial é a repartição dos encargos entre estados e municípios cuja proporcionalidade é exigida por lei. $\mathrm{Na}$ prática, porém, é preciso verificar se tal exigência vem sendo respeitada.

Outro ponto do FUNDEF a ser aqui analisado é a valorização dos professores cujos salários são reconhecidamente baixos e incapazes de provocar um amplo acesso e uma permanência na carreira. É verdade que a Lei no 9.424/96 obriga à construção de uma carreira docente (no ensino fundamental) cuja virtude continua esbarrando no financiamento, na carência de informações, no próprio terreno da moralidade pública, além dos novos constrangimentos legais advindos dos novos controles sobre os orçamentos dos estados e dos municípios. Isso não anula os benefícios do FUNDEF com relação a regiōes do país nas quais o desenho desse Fundo operou avanços quanto aos salários de professores.

O contraponto aqui é a situação difícil dos estados com relação à pressão advinda dos grupos que pleiteiam o ensino médio. Idêntica 
é a situação dos municípios com relação à educação infantil e à educação de jovens e adultos, atualmente fora do FUNDEF. O problema é que, ao otimizar e racionalizar o modelo de financiamento para o ensino fundamental, houve uma mudança na sustentação das outras etapas e uma redistribuição dos recursos, as quais, sem novas fontes, ficam em dificuldades para atender a demandas outras, hoje tão importantes quanto o ensino fundamental. Cria-se, pois, um campo de tensão entre os direitos proclamados, o dever do Estado e a sustentabilidade de ações na área. Esse campo de tensão não tem saída sem o concurso de uma discussão e efetivação posterior do significado do que vem a ser princípio da colaboração recíproca entre os entes federativos posto na Constituição e na LDB.

Por outro lado, resulta estranha uma exigência de carreira docente para o ensino fundamental, sendo que esta se põe como a segunda etapa da educação básica. Ou seja, por que não uma carreira para a educação básica? Por que privilegiar, sob um imperativo nacional, apenas o "meio", deixando "as pontas" de fora?

$\mathrm{O}$ terceiro ponto refere-se à criação dos Conselhos Fiscais e de Controle. Graças ao empenho de parlamentares de oposição e de grupos interessados no assunto, a emenda incorporou a instituição de um Conselho Nacional do FUNDEF ao lado dos Conselhos Estaduais e Municipais. Eles são instrumentos de cidadania, de democracia e de controle do Estado. Implicam o cidadão com os destinos da escola, ampliam os espaços públicos de decisão, têm a função de democratizar a informação para todos e podem controlar desmandos do poder. São uma promessa de participação que se vê realizada em experiências exitosas em vários municípios do país.

O contraponto é, em primeiro lugar, nossa forte tradição de “estadania”, no dizer de José Murillo de Carvalho, e fraca tradição no que se refere à presença e instituição de conselhos de controle da cidadania. Isso restringe essa promessa pois nem em todos municípios eles se implantaram e, muitas vezes, onde se constituíram, o que deveria ser transparente e de domínio público acaba se tornando mais um espaço a ser coberto pelo mandonismo e pela troca de favores. Ou seja, um instrumental público que se vê privatizado pelos interesses avessos à transparência do poder.

O quarto ponto é o da presença dos Tribunais de Contas. Eles passaram a ter uma atuação distintiva e importante, pois dos relatórios deles depende boa parte da liberação de verbas e de transferências. Aqui se deve louvar o esforço que eles vêm fazendo a 
fim de se inteirar de dados, cobrar aplicações corretas e até mesmo avançando em seus deveres ao entenderem que tão importante quanto a correta aplicação é a existência de conseqüências positivas desta política para o ensino fundamental.

O contraponto é a pouca circulação das informações dos Tribunais de Contas pelos Conselhos Fiscais, a baixa articulação entre outros pólos de controle e a protelação de medidas cabíveis como consequiência da aplicação equivocada dos recursos. Em contrapartida, se o Tribunal de Contas da União pode cobrar dos estados a adequação à lei e se os Tribunais dos Estados podem fazer o mesmo com relação aos municípios, quem pode cobrar as mesmas coisas da União? Corretamente se pode responder que se trata do Tribunal de Contas da União. Pode parecer estranho, mas a emenda que pune estados e municípios até mesmo com intervenção, segundo os art. 34, V, e 35, III, da Constituição, não se refere ao Tribunal de Contas da União. O papel deste último é tácito ao passo que sua presença com relação aos governos subnacionais é explícita.

Isso nos conduz ao quinto ponto. Crucial no FUNDEF é a presença articuladora, supletiva, técnica e redistributiva da União, tal como disposta na LDB nos art. $8^{\circ}$ e 75 em face do conjunto da educação nacional. Articular e redistribuir é uma tarefa que cabe a todos os entes federativos e não só a estados, municípios e Distrito Federal. Por isso deixa de ser compreensível que o governo federal cobre a adequação dos outros entes federativos à Emenda no $14 / 96$ e às leis no $9.394 /$ 96 e no $9.424 / 96$, e ele, que lutou tanto pelas suas respectivas aprovaçôes e que foi, na verdade o redator dos principais artigos, seja desobediente à emenda e às leis. A situação é clara e constrangedora ao mesmo tempo. Basta citar o art. $6^{\circ}, \$ 1^{\circ}$, da Lei ${ }^{\circ} 9.424 / 96$.

O valor mínimo anual por aluno, ressalvado o disposto no $\$ 4^{\circ}$, será fixado por ato do Presidente da República e nunca será inferior à razão entre a previsão da receita total para o Fundo e a matrícula total do ensino fundamental no ano anterior, acrescida do total estimado de novas matrículas, observado o disposto no art. $2^{\circ}, \$ 1^{\circ}$, incisos I e II.

Ora, se o $\$ 4^{\circ}$ fixava o valor mínimo anual para 1997 em 300 reais, o que se vê a partir daí é um valor arbitrário, abaixo do que foi fixado em lei e - repito - com apoio e até mesmo formulação do texto do e pelo governo. E é isto o que é constrangedor, pois está havendo uma infração à lei e uma ruptura com o princípio fundamental da democracia de igualdade perante a lei. Segundo deter-

Educ. Soc., Campinas, v. 23, n. 80, setembro/2002, p. 168-200 
minados cálculos da Uniāo dos Dirigentes Municipais de Educação (UNDIME), entre 1998 e 2001, a União deixou de repassar perto de 6,2 bilhões de reais aos Fundos Estaduais por não ter cumprido o que reza o texto da lei.

Ainda que o FUNDEF represente uma dimensão peculiar do sistema federativo, não se podem analisar as políticas educacionais sem dimensionar a presença dos entes federados. São os estados e os municípios que levam adiante a implementação dessas políticas, especialmente no disciplinamento financeiro. Desse modo, várias facetas da educação básica são levadas adiante pelos entes federados. É na concretude dos mesmos que se pode também ver a diversidade (política, inclusive) de caminhos que os diferentes governos de diferentes partidos ou composições partidárias estão implementando. E, dado nosso sistema político, a face de uma descentralização é imprescindível de ser considerada para uma análise objetiva. É preciso, pois, fazer estudos de caso, comparar situaçóes e dimensionar, na concreção de uma política educacional, os limites, as redefiniçóes e as possibilidades que o regime federativo introduz.

O nosso federalismo nutre-se também de disparidades regionais que afetam a capacidade financeira e administrativa dos governos subnacionais. São 27 estados e mais de 5.500 municípios. No caso dos municípios, a situação agrava-se, pois eles são muito diversos em sua capacidade financeira e não poucos vivem à base de transferências dos governos estaduais e do próprio governo federal.

Contudo, fator que na década de 1990 avultou de maneira muito significativa foi a presença dos órgãos internacionais, distinguindo-se os órgãos multilaterais de financiamento como as agências do Banco Mundial (do tipo BID e BIRD), dos órgãos voltados para a cooperação técnica (do tipo UNICEF e UNESCO). Como os caminhos da globalização implicaram a reforma do Estado e como esta significou um grande afastamento do Estado de vários campos de atividade, com o enxugamento das contas públicas, boa parte dos investimentos em educação não foi contemplada com a poupança interna. Desse modo, o investimento externo acertado junto a Bancos investimento que é dívida a pagar - foi mais do que um empréstimo. Ele veio acompanhado de critérios contratuais (nem sempre transparentes) e mesmo de metodologias já predefinidas.

Se, de um lado, a vinculação orçamentária amortece o impacto deste fator, por outro lado, a dependência a tais liames não pode ser desprezada. Mas também não deve ser superdimensionada, seja por 
conta dos diferentes governos próprios do federalismo, seja por conta da massa crítica gerada, sobretudo, pelos programas de pós-graduação que têm atuado nos órgãos governamentais com capacidade crítica ou têm elaborado críticas a esses liames que circundam aspectos próprios da autonomia dos Estados Nacionais. Cumpre verificar, caso a caso, como concretamente esses programas foram implementados em distintos estados ou municípios e qual o modo de recepção destes programas, a fim de não se generalizar como realização o que é um programa e a fim de não incidir em um mecanicismo.

Uma quarta preliminar, determinante de nossa situação, é a extrema desigualdade socioeconômica que atende pelo nome de pobreza ou de miséria e significa a exclusão histórica e atual de um número significativo de estudantes provindos de famílias de baixa renda. Essa desigualdade, hoje medida por vários instrumentos de análise (do tipo IDH), faz com que haja problemas na escola e que não são da escola e por isso mesmo não é desprezível o impacto desta situação de fato sobre o conjunto do sistema educacional. Se 35 milhôes de alunos estão matriculados no ensino fundamental, só 9 milhões estão no ensino médio, dos quais apenas 1,8 milhão concluem essa etapa do ensino. É de se perguntar se se pode desconsiderar a desigualdade socioeconômica como geradora remota das dificuldades próximas que afetam o desempenho intra-escolar dos alunos.

Se a qualidade da educação básica, portanto, não é exclusiva ou privativa de nenhuma de suas etapas e/ou modalidades, então o caráter indispensável articulado à cidadania e ao trabalho é próprio de toda a educação básica.

Contudo, o FUNDEF acabou por focalizar o ensino fundamental que é a etapa "intermediária" da educação básica. E as etapas de "defesa" (educação infantil) e do "ataque" (ensino médio)?

O ensino fundamental, obrigatório, gratuito e de oito anos, cujo acesso está em vias de se tornar cada vez mais universalizado, vê-se protegido com os mais diversos instrumentos de asseguramento como obrigatoriedade, direito público subjetivo, controle de faltas, proteção jurídica pelo ECA e pelo Código Penal e FUndef.

Muitos outros programas nasceram em prol do ensino fundamental. É o caso do FUnDESCOLA e do Projeto Nordeste.

O fundescola ou Fundo de Fortalecimento da Escola, financiado com recursos do governo federal e de empréstimos do Banco Mundial, é um programa do Ministério da Educação que tem por 
objetivo promover ações para a melhoria da qualidade das escolas do ensino fundamental. Desenvolvido em parceria com as secretarias estaduais e municipais de Educação, pretende ampliar a permanência das crianças nas escolas públicas nas regiões Norte, Nordeste e Centro-Oeste. O programa visa também a aumentar o desempenho dos sistemas de ensino público, a capacidade técnica das secretarias de Educação e a participação social.

O programa é implantado principalmente em zonas de atendimento prioritário formadas por microrregióes com municípios mais populosos definidas pelo Instituto Brasileiro de Geografia e Estatística (IBGE).

Há também programas compensatórios como Bolsa-Escola, criado pela Medida Provisória no 2.140, de 13 de fevereiro de 2001, aprovado pelo Congresso Nacional em 27 de março de 2001. Ele foi sancionado pelo presidente da República, por meio da Lei $\mathrm{n}^{\mathrm{o}}$ 10.219, de 11 de abril de 2001. Tecnicamente é o Programa Nacional de Renda Mínima vinculada à educação - "Bolsa-Escola" - e manifesta-se como uma estratégia compensatória de combate à pobreza via concessão de incentivo financeiro mensal às famílias em situação de pobreza. Ele tem como contrapartida a manutenção da criança na escola.

Vê-se, pois, que o ensino fundamental é objeto de uma política de focalização. Mesmo assim, as estatísticas apresentam quase 3 milhōes de crianças e adolescentes em idade escolar fora da escola e as avaliações manifestam baixas taxas de conclusão e baixa qualidade.

A educação infantil, dever do Estado, tornou-se etapa constitutiva da organização da educação nacional sob a educação básica. Com isso, acertadamente, ela perdeu a condição anterior de área assistencial. Ela é da responsabilidade administrativa prioritária dos municípios. Contudo, do ponto de vista financeiro e técnico, tal responsabilidade deve ser compartilhada com a União e os estados, de acordo com o art. 30, VI, e com o art. 211, $\$ 1^{\circ}$, da Constituição. Entretanto, os dados estatísticos, as análises das associações de municípios e mesmo os trabalhos de pesquisa acadêmica dos programas de mestrado e de doutorado e de instituiçôes especializadas vêm demonstrando que tal partilha financeira não está ocorrendo e, assim, o ônus da educação infantil tem ficado com os municípios. Trata-se, portanto, de claro recuo de entes estaduais e da União, implicados obrigatoriamente na sustentação da oferta desta etapa da educação, e de transferência de ônus sem o devido respaldo, 
sabendo-se que a lei do Fundo não a contempla com o financiamento subvinculado. Tanto isso é verdade que o próprio Plano Nacional de Educação o reconhece como tal na meta de ${ }^{\circ} 25 \mathrm{~d}$.

Sendo a educação infantil a base da educação básica, tendo apenas 5 milhões de crianças nessa etapa, estamos longe de um acerto de contas com a democratização dessa forma de educação, especialmente se ela ficar apenas sob a responsabilidade municipal. Se estamos longe ainda de uma expansão nessa etapa, isso não pode significar que os $10 \%$ dos recursos que não ficaram subvinculados ao FUNDEF e os $25 \%$ dos impostos que não compóem o FUNDEF não devam ser rigorosamente aplicados em educação infantil.

De todo o modo, analisar as políticas públicas dessas etapas da educação básica é não só enfrentar as políticas exaradas pela União mas também enfrentar o que está se passando, de fato, no âmbito dos mais de 5.500 municípios distribuídos pelos 27 estados da Federação.

Nesse sentido, é importante considerar que a política educacional é mais ampla do que as iniciativas ou omissōes estatais. $\mathrm{O}$ campo da educação infantil tem sido farto em pressōes sociais com vistas à ampliação da rede física por parte das famílias de classes populares. Isso faz supor também o aumento da consciência da importância dessa etapa não só como direito dos pais ao trabalho como também um direito da própria infância como um momento significativo da construção da personalidade.

Valeria a pena debruçar-se também sobre as experiências de municípios que constroem a etapa do ensino fundamental de seus sistemas de ensino a partir dos 6 anos de idade. Isso pode sinalizar caminhos para a meta de número dois do ensino fundamental tal como sinalizada no Plano Nacional de Educação.

O ensino médio é outro momento complexo e significativo da educação básica. Torna-se imperativo focalizar um ponto desta complexidade que se mescla com o ordenamento jurídico e é parte dele ao mesmo tempo.

O ensino médio, legalmente uma competência dos estados pela LDB, tornou-se explicita e vinculadamente uma atribuição prioritária destes com a Lei no 9.424/96, a lei do FUNDEF.

A lei assegura o ensino médio como a etapa conclusiva da educação básica, com três anos de duração e com um mínimo de 2.400 horas de 60 minutos. O ensino médio, assim entendido, tornou-se constitucionalmente gratuito e também, por lei ordinária, 
"progressivamente obrigatório". A indicação do "progressivamente obrigatório" era constitucional e foi desconstitucionalizada pela Emenda $n^{\circ} 16 / 96$. Uma alteração ainda não devidamente analisada...

Legalmente, então, o ensino médio - gratuito no âmbito do ensino público - deixou de ser independente do conjunto da educação básica, compondo-se com ela e tornando-se progressivamente obrigatório.

Assim, do ponto de vista jurídico, consideradas as três funçōes clássicas atribuídas ao ensino médio: a função propedêutica, a função profissionalizante e a função formativa, é esta última que agora, conceitual e legalmente, predomina sobre as outras. Legalmente falando, o ensino médio não é, como etapa formativa, nem porta para o ensino superior e nem chave para o mercado de trabalho. Ele tem uma finalidade em si, embora seja requisito tanto do ensino superior quanto da educação profissional de nível técnico.

Entretanto, mostrando-se um governo forte para implantar sua política, vem à luz o Decreto $n^{\circ} 2.208 / 97$ que tornou o ensino médio co-requisito para cursos de educação profissional de nível técnico e o seu certificado conclusivo tornou-se pré-requisito para o diploma da educação profissional de nível técnico. Isto será melhor visto adiante.

De modo semelhante ao que se disse com relação ao ensino fundamental, analisar políticas públicas do ensino médio, hoje, é tanto considerar as iniciativas nacionais cabíveis à União quanto mergulhar nos projetos dessa etapa da educação no conjunto dos 27 estados da federação. Se há a presença executiva do governo federal e da presença normativa do Conselho Nacional de Educação, é preciso considerar outros lugares específicos dos quais também emanam coordenadas próprias para a composição da política de educação. São eles: os governos estaduais, o Conselho Nacional dos Secretários de Educação (CONSED) e os Conselhos Estaduais de Educação e seu respectivo Fórum.

De parte do governo federal, além da atuação na proposta de Parâmetros Curriculares do Ensino Médio ( $\mathrm{PCNs}$ ), há que se considerar suas iniciativas específicas nessa etapa do ensino.

Sob a legislação em vigor, cabendo à União ação redistributiva e supletiva, os estados e o Distrito Federal são responsáveis pela oferta e pelo financiamento do ensino médio. Assim, o Ministério da Educação criou o Projeto Escola Jovem, financiado parcialmente com 
recursos do Banco Interamericano de Desenvolvimento (BID). Tratase de um empréstimo que é contraído pelo governo federal, que o repassa aos estados por meio de projetos cuja aprovação depende do aceite dos objetivos gerais da reforma do ensino médio.

O Projeto Escola Jovem tem como metas: implementar a reforma curricular e assegurar a formação continuada de docentes e gestores de escolas de ensino médio; equipar progressivamente as escolas de ensino médio com bibliotecas, laboratórios de informática e ciências e Kit Tecnológico, para recepção da TV Escola; criar 1,6 milhão de novas vagas; melhorar os processos de gestão dos sistemas educacionais das unidades federadas; redefinir a oferta de ensino médio, com a criação de uma rede de escolas para jovens.

Além disso, à vista das disparidades entre as unidades da Federação, outro projeto, denominado Alvorada, foi elaborado considerando-se, pelo critério do IDH inferior à mediana do país, 14 estados encontrados nesta situação. São eles: Acre, Alagoas, Bahia, Ceará, Maranhão, Pará, Paraíba, Pernambuco, Piauí, Rio Grande do Norte, Rondônia, Roraima, Sergipe e Tocantins. Esses estados podem submeter plano de trabalho ao governo federal para o apoio ao Desenvolvimento do Ensino Médio.

Por sua vez, a Lei no $10.127 / 2001$, ou seja, o Plano Nacional de Educação (PNE), em seu diagnóstico do ensino médio, acusa uma população entre 15 e 18 anos com 16.580.383 habitantes em 1997, dos quais 5.933.401 matriculados no ensino médio. Este número se divide, por dependência administrativa público/privado, em $73 \%$ $\mathrm{X} 27 \%$. Este número se amplia para 7 milhōes de matrículas em 1998 e para 7,8 milhões em 1999 (81\% X 19\%). O Censo Escolar 2001 (MEC/INEP) mostra 8,4 milhões de matrículas no ensino médio com um total de 1,8 milhão de concluintes.

O mesmo diagnóstico de 1997, citado no PNE, revela, porém, um reduzido acesso ao ensino médio. De uma população de 17 milhões na faixa de 15 a 19 anos, havia só 6 milhões de estudantes matriculados. Também é grande o número de adultos que volta à escola, vários anos após o ensino fundamental. Assim, o atendimento acima da idade prevista, ou seja, 3,8 milhões ou 53,8\%, está acima de 17 anos. No conjunto dos quase 7 milhões, 3,8 milhões são estudantes do noturno, o que faz supor que a maioria destes já esteja no mercado de trabalho. E em termos de rede física, o ensino médio acaba por ocupar e até competir com as instalaçôes do ensino 
fundamental. Só $32 \%$ da faixa etária de 15 a 17 anos - faixa considerada legalmente apropriada - está matriculada nas escolas.

Por decorrência, só em 2011, o ensino médio tornar-se-ia obrigatório e, nessa medida, seria considerado direito público subjetivo.

Estamos longe, pois, da universalização do ensino médio, o que é reconhecido em lei. $\mathrm{O}$ PNE assinala 20 metas para o ensino médio. A primeira meta postula a implementação de condições que assegurem, no início do ano letivo de 2004, o atendimento da totalidade dos egressos do ensino fundamental e que, em cinco anos, assegure-se o atendimento de $50 \%$ da demanda e, em dez anos, $100 \%$ da demanda do ensino médio. Isso significa que, por projeção legal, o atendimento integral da demanda só se fará em 2010 .

Mas, e os recursos para tal se temos vetos presidenciais, determinados pelo setor econômico do governo, que impedem a progressão do porcentual do PIB para aplicação em educação?

A capacidade de atendimento do ensino médio e seu respectivo financiamento têm sido objeto de preocupação constante do CONSED, sobretudo em função do término legal do FUNDEF em 2006. Em diversas ocasiões, o CONSED vem se posicionando ante a situação da escola pública de ensino médio tal como se apresenta neste momento. Em especial há grande preocupação com os recursos correspondentes à complementação da União para o FUNDEF, na medida em que eles estão sendo retirados dos recursos constitucionalmente definidos para a manutenção e o desenvolvimento do ensino e não do salário-educação (Carta de Teresina, 1999). Essa Carta denuncia, sob a redação da Emenda no 14/96 que estabelece para a União, na sua parte cabível do FUNDEF, o equivalente a $30 \%$ dos $18 \%$ constitucionalmente vinculados, o não-cumprimento do estabelecido. Por isso - continua o CONSED - é indispensável a revisão imediata do cálculo aluno/ano (Carta de Brasília, 1999), já que o cálculo do valor por aluno, efetivado pelo governo federal, diverge do estabelecido na Lei $n^{\circ}$ 9.424/96. Afinal, além de dar conta do ensino médio, continua o CONSED, os estados são responsáveis por cerca de dois terços dos recursos do FUndef (Carta de Rio de Janeiro, 2000). Entre tantas Declarações e Cartas percebe-se que os valores atuais para o ensino médio são insuficientes e, tendo em vista a pressão pela ampliação da própria rede física dessa etapa de ensino, vai se tornando inviável, nos termos do CONSED, financiar a ampliação do ensino médio. 
O Conselho Nacional de Educação já normatizou, praticamente, todo o conjunto das etapas e modalidades da educação básica por meio de Pareceres e Resoluções. Neste sentido, cumpre verificálos e, sobretudo, analisá-los, sabendo-se que o CNE disponibiliza tais documentos pela via comum da revista Documenta, por CD-ROM e por publicação própria.

Os Conselhos Estaduais de Educação e as respectivas normatizações, ainda em fase de processamento, devem ser objeto de uma análise específica. $\mathrm{Na}$ verdade, os Conselhos têm tido uma atuação mais evidente nos casos escabrosos dos que, de modo irresponsável, fazem oferta de cursos e exames de EJA. Recentemente, o MEC, por meio do INEP, criou por decreto o Exame Nacional de Certificação de Conclusão da Educação de Jovens e de Adultos (EnCCEja). Por meio dele, os estados (que gozam de prerrogativa nesta matéria) poderão, via adesão voluntária, articular-se com o INEP na oferta de exames supletivos. Não se pode ignorar que muitos estados contam com uma sistemática própria de oferta para tais exames e que mereceriam apoio neste assunto. Muitos estados já conduzem os exames supletivos de jovens e adultos com bastante cuidado e rigor e, em muitos cursos, o processo é integralmente presencial e com avaliação no processo. Contudo, a via alternativa proposta pelo INEP tem sido apresentada mais como um corretivo de abusos perpetrados por instituiçôes inescrupulosas do que uma referência nacional e um caminho para um grau maior de isonomia entre os estudantes que concluem os estudos na idade legalmente apropriada e os que o fazem pela via dos cursos de educação de jovens e adultos e de exames supletivos.

Por se falar em EJA, ela foi objeto de um veto presidencial que a retirou do FUNDEF. Se a primeira justificativa técnica para o veto era procedente (falta de estatísticas confiáveis), o INEP logo corrigiu tal fato, o que levaria à derrubada do veto. Os sucessivos protestos, associados ao fato de ser a EJA do ensino fundamental um direito público subjetivo, acabaram por forçar o governo a oferecer uma alternativa, também focalizada, sobre o assunto. Foi criado um "FUNDEF seletivo" em moldes iguais ao do ensino fundamental das crianças de 7 a 14 anos e em moldes similares ao Projeto Alvorada. Focalizando os sistemas públicos dos municípios mais pobres de estados pobres (critério do IDH), o programa só atinge jovens e adultos entre 15 e 29 anos. Os recursos são orçamentários e destinados às escolas públicas. 
A EJA, desde que respeitadas as idades de exames previstas em lei, volta-se tanto para o ensino fundamental como para o ensino médio.

Assim, seja pelo lado da denominada idade legal apropriada, seja pelo lado da EJA, o ensino médio tem uma interface com a educação profissional de nível técnico.

De acordo com a Lei $n^{\circ} 9.394 / 96$, art. $36, \$ 2^{\circ}$, “o ensino médio, atendida a formação geral do educando, poderá prepará-lo para o exercício de profissões técnicas". Já o $\$ 4^{\circ}$ do mesmo art. 36 estabelece uma distinção entre "a preparação geral para o trabalho", certamente para fazer jus ao artigo 205 da Constituição Federal de 1988, e a "habilitação profissional" cujo desenvolvimento pode ser feito ou nos próprios estabelecimentos de ensino médio ou em cooperação com instituições especializadas. Por outro lado, o art. 40 da LDB usa a expressão "articulação" na interface entre o ensino médio e a educação profissional de nível técnico.

Neste sentido, a lei não impediria uma integração entre o ensino médio e educação profissional de nível técnico, obviamente resguardadas as 2.400 horas de 60 minutos e a função formativa da etapa conclusiva da educação básica. O termo "articulação" como ponto de composição ou como ponto de conexão entre dois segmentos de uma mesma realidade permitiria a integração como uma possibilidade organizacional. Mas deve-se reconhecer, todavia, uma redação pouco cartesiana do $\$ 2^{\circ}$ do art. 36 da LDB.

A ambigüidade redacional do artigo ou até mesmo uma interpretação de caráter ambivalente de outros artigos da própria Lei deveria ser objeto de regulamentação própria dos órgãos normativos. No caso, por se tratar de uma lei nacional, trata-se de atribuição do Conselho Nacional de Educação. Contudo, no âmbito de um federalismo tensionado entre o jurídico/formal e o real/vigente, o executivo emitiu o Decreto no 2.208 de 17 de abril de 1997. Esse decreto teve como objetivo regulamentar justamente o $\$ 2^{\circ}$ do art. 36 e os artigos de 39 a 42 da LDB. Categorizada a educação profissional de nível técnico, por esse decreto, em básica, técnica (nível médio) e tecnológica (nível superior), estas três modalidades acolhem perto de 3 milhōes de estudantes, segundo as estatísticas oficiais.

Ora o art. 50 do decreto diz: "A educação profissional de nível técnico terá organização curricular própria e independente do ensino médio, podendo ser oferecida de forma concomitante ou seqüencial a este". 
Com isso, a interpretação do $\$ 2^{\circ}$ do art. 36, que, a rigor, necessitava de explicação e de interpretação pelo órgão normativo próprio, tornou o ensino médio independente da e articulado com a educação profissional de nível técnico, vedada a possibilidade de integração.

Dessa maneira, a matrícula no ensino médio é condição de possibilidade para a matrícula na educação profissional de nível técnico e o certificado de conclusão do ensino médio é conditio sine qua non do diploma de técnico.

Mas, se antes da Constituição de 1988 não havia um princípio nacional que garantisse a gratuidade do ensino do então $2^{\circ}$ grau, este, quando oferecido, era gratuito na prática ou por injunção de uma Constituição Estadual, ou mesmo lei ordinária estadual. O financiamento do $2^{\circ}$ grau tornava-se imanente ao dever de Estado. Numa palavra: a educação profissional era responsabilidade de Estado e financiada por ele.

Agora, o ensino médio (formação geral) é dever de Estado devendo ser oferecido de modo gratuito nos estabelecimentos públicos sob a função formativa. Trata-se de um avanço inconteste. Mas com a definição do Decreto no 2.208/97 estabelecendo o caráter independente e separado da educação profissional do ensino médio, ainda que articulado a este, e sem um apoio legal explícito no que concerne à gratuidade e ao financiamento, ela não tem mais um responsável claro e distinto.

A educação profissional tornou-se órfã do dever de Estado em matéria de financiamento e sua responsabilidade ficou diluída. É crescente a presença do Ministério do Trabalho nesta área, sobretudo em cursos de educação profissional de nível básico (atente-se para a ambigüidade do termo "básico" tal como expresso no Decreto e tal como posto na LDB...) por meio do Fundo de Apoio ao Trabalhador (FAT). É nesta disjunção organizacional que ganha sentido o discurso e a prática das parcerias que, sem negar seu caráter supletivo, não podem assumir função primordial cabível aos poderes públicos.

Da mesma maneira, o ensino normal de nível médio - com a interpretação (equivocada e ilegal) da obrigatoriedade imperativa do ensino superior para a docência na educação infantil e nos quatro primeiros anos de escolarização - tem se tornado outro órfão, melhor dizendo, um candidato a um desaparecimento perverso ou a um abandono em zonas ou regióes em que ele continua imprescindível. 
É verdade que o Ministério da Educação criou o Programa de Expansão da Educação Profissional (PROEP) em novembro de 1997. O PROEP tem duração até 2006 e conta com recursos de 500 milhões de dólares dos quais a metade vem pelo Banco Interamericano de Desenvolvimento (BID) sob a forma de empréstimo. A outra metade compóe-se de recursos advindos do orçamento do MEC e do Fundo de Apoio ao Trabalhador (faT) do Ministério do Trabalho. O proep tem como objetivo subsidiar a implantação da nova proposta de educação profissional. Os recursos são repassados mediante convênios com as escolas da rede federal, com as secretarias estaduais de Educação e Ciência e Tecnologia, e com o segmento comunitário. Estão em andamento 57 projetos federais com pouco mais de 120 milhões de reais, 137 projetos estaduais com perto de 275 milhões de reais e 107 projetos comunitários com perto de 259 milhôes de reais. E há 301 projetos escolares perfazendo quase 660 milhões de reais.

Passando agora das etapas da educação básica para o sensível ponto da política voltada para os componentes curriculares, cumpre diferenciar o que são Diretrizes Curriculares Nacionais do que são os Parâmetros Curriculares Nacionais.

As diretrizes curriculares, postas na Lei no $9.131 / 95$, devem explicitar os dispostos no art. 22, XXIV, e no art. 210 da Constituição Federal de 1988, que dizem, respectivamente:

Compete privativamente à União legislar sobre:

(...)

Diretrizes e bases da educação nacional;

Serão fixados conteúdos mínimos para o ensino fundamental, de maneira a assegurar formação básica comum e respeito aos valores culturais e artísticos, nacionais e regionais.

Além desse artigo, há na Constituição outros dispositivos relativos a componentes curriculares como, nas Disposiçôes Constitucionais Gerais, o art. 242, e $1^{\circ}$, e o art. 215, e $1^{\circ}$. Estes dois dispositivos se coadunam com aquele expresso no capítulo da educação, conforme art. 210, e $2^{\circ}$ : "O ensino fundamental regular será ministrado em língua portuguesa, assegurada às comunidades indígenas também a utilização de suas línguas maternas e processos próprios de aprendizagem".

E há também o art. 225 sobre meio ambiente. 
Enfim, o princípio do pleno desenvolvimento da pessoa, segundo o art. 205, certamente implica o conhecimento de fatores que conduzem a escola a não ignorar o direito à saúde (cf. art. 227), já que se trata de um dever do Estado, da família e da sociedade (cf. art. 227 e art. 190). Esse dever, com certeza, implica tanto uma orientação preventiva contra os assaltos provindos das doenças sexualmente transmissíveis, quanto uma orientação valorativa da sexualidade.

Os dispositivos constitucionais referentes direta ou indiretamente a currículos foram promulgados pela Assembléia Nacional Constituinte, não sem antes ter havido intensa discussão sobre eles. Vários atores políticos, governamentais e não-governamentais, por exemplo, polemizaram sobre a correlação entre formação básica comum, currículo mínimo e outros pontos relativos a componentes curriculares. Os atores que se pautaram pela defesa de uma formação básica comum lograram a constitucionalização de um dispositivo que, antes, jamais ultrapassara os limites da legislação infra-constitucional.

O prosseguimento da discussão dessa temática ocorreu em torno de projetos da Lei de Diretrizes e Bases da Educação Nacional, cuja tramitação vem desde 1988, e também por ocasião do Plano Decenal de Educação para Todos, em 1994.

Mas não se pode esquecer que, com maior ênfase no ensino fundamental, já havia orientações significativas postas pela Lei ${ }^{\circ}$ 8.069 de 13/7/1990, mais conhecida como Estatuto da Criança e do Adolescente (ECA). Além da importância geral desse Estatuto para as crianças e os adolescentes no processo educativo, há que se ressaltar a relevância de dois artigos. Dizem eles respectivamente:

Art. 57: O Poder Público estimulará pesquisas, experiências e novas propostas relativas a calendário, seriação, currículo, metodologia, didática e avaliação, com vistas à inserção de crianças e adolescentes excluídos do ensino fundamental.

Art. 58: No processo educacional respeitar-se-ão os valores culturais, artísticos e históricos próprios do contexto social da criança e do adolescente, garantindo-se a estes a liberdade de criação e o acesso às fontes de cultura.

Ora, a Lei no 9.131/95, que (re)criou o Conselho Nacional de Educação (CNE), atribui à Câmara de Educação Básica (CEB), entre outras competências, no art. 9o, letra c, a de deliberar sobre as diretrizes curriculares propostas pelo MEC... Logo, cabe ao CNE deliberar sobre essas diretrizes propostas. 
Contudo, a (re)criação do CNE já havia sido objeto de uma medida provisória desde o Governo Itamar e a Lei de Diretrizes e Bases estava sendo objeto de discussão parlamentar. Com a posse do governo eleito em 1994, o campo estava indefinido e o MEC exercia as funçôes de órgão executivo e de órgão normativo.

Ora, desde a eleição de Fernando Henrique Cardoso, a equipe de governo havia tomado a iniciativa de trazer à agenda política a discussão do que denominou Parâmetros Curriculares Nacionais (PCNs), antes da Lei no 9.131/95 e da Lei no 9.394/96. Tratava-se de materializar um projeto de governo relativo à educação, no que se refere a currículos escolares.

As muitas "transições" em processo, as ausências e vacâncias, a expectativa de uma nova lei de diretrizes e bases, a existência de dois projetos de diretrizes e bases, a vontade de implementar programas em início de governo determinaram no MEC a superposiçãa de papéis que eram dele e de outros tantos que apenas provisoriamente estavam nele. A resultante foi a elaboração dos PCNs como se fossem a tradução do art. 210 da Constituição Federal.

Não seria fácil chegar à consciência de que se deveria distinguir papéis cruzados e superpostos.

Da proposição inicial dos PCNs, feita pela Secretaria de Educação Fundamental (SEF/MEC), consta uma série de textos didáticos voltados para os currículos das escolas de ensino fundamental e divididos por áreas de conhecimento. A partir disso, antes mesmo da Lei no 9.131/95 e da Lei no 9.394/96, até mesmo para propor um campo de atuação próprio de governo, a SEF deu a conhecer esses textos nas unidades federativas. Lá se fizeram presentes apresentaçóes, debates, apoios e contestaçóes quanto à metodologia utilizada e também quanto à competência legal do MEC neste assunto.

Destes encontros e desencontros, o MEC reelaborou sua versão preliminar e a nova versão dos PCNs foi então apresentada formalmente ao Conselho Nacional de Educação em 10/9/1996.

$\mathrm{Na}$ exposição de motivos que acompanhou a apresentação dos PCNs, diz o ministro:

Cumprindo o dispositivo constitucional, que em seu artigo 210 determina a fixação de conteúdos mínimos para o ensino fundamental, atendendo aos indicadores apontados pelo diagnóstico levantado pelo Plano Decenal, e concretizando suas diretrizes (...). 
Entendemos que a pertinência de uma referência curricular para o país está na garantia ao direito de todo aluno brasileiro de usufruir do conjunto de conhecimentos cientificamente elaborados e historicamente acumulados que, articulados com o respeito às características regionais, sejam imprescindíveis ao exercício efetivo da cidadania.

O primeiro parágrafo dessa exposição de motivos mostra que o MEC busca, por intermédio dos PCNs, preencher o disposto no art. 210 da Constituição e concretizar as diretrizes do Plano Decenal. Portanto, uma vez que o art. 210 não explicita nem o sujeito e nem o instrumento pelo qual os conteúdos serão fixados, parece que o MEC se definiu como este sujeito.

Por outro lado, a Lei no 9.131/95 diz que é tarefa das Câmaras de Educação Superior e de Educação Básica, de acordo com as respectivas competências, deliberar sobre as diretrizes propostas pelo MEC. Ora, o material enviado pelo MEC ao Conselho não é o conjunto de conteúdos mínimos e obrigatórios para o ensino fundamental e também não é, direta e imediatamente, uma proposta de diretrizes. Ele é um complexo de propostas curriculares em que se mesclam diretrizes axiológicas, orientações metodológicas, conteúdos específicos de disciplinas e conteúdos a serem trabalhados de modo transversal e sem o caráter de obrigatoriedade próprio da formação básica comum do art. $210 \mathrm{da}$ CF/88.

A Câmara de Educação Básica, ao analisar o conjunto dos Parâmetros, exerceu sua função de assessoria, de acordo com o art. $7^{\circ}$, letra c, da Lei $n^{\circ} 9.131 / 95$. Sem se ater ao detalhamento dos Parâmetros, próprio, aliás, de programas curriculares, a Câmara buscou exercer sua função deliberativa em obediência aos princípios constitucionais e à legislação pertinente.

Sob esses princípios, sempre tendo em vista a democratização da educação, a Câmara buscou também depreender diretrizes implícitas ou explícitas nos PCNs e na exposição de motivos quando do envio dos Parâmetros ao Conselho, já que os textos enviados não continham expressamente uma proposição de diretrizes tal como determina a Lei $n^{\circ} 9.131 / 95$.

Coube, então, à Câmara tomar decisão, deliberar, não sobre programas de currículo, mas sobre os princípios e as diretrizes que neles devem estar presentes. Cabe-lhe, outrossim, fixar aqueles conteúdos considerados mínimos para a formação básica do cidadão.

Os textos revelam que os PCNs são propostas detalhadas de conteúdos que incluem conhecimentos, procedimentos, valores e 
atitudes no interior de disciplinas, áreas e matérias articulados em temas que se vinculam às várias dimensões da cidadania.

Os conteúdos dos PCNs abrigam os conhecimentos já atinentes ao ensino fundamental, transmitidos por meio de componentes curriculares, tais como língua portuguesa, ciências, história/geografia, matemática, artes e educação física. Ao lado desses componentes, introduziu-se aí uma novidade por meio dos temas transversais (saúde, ecologia, orientação sexual, ética e convívio social, pluralidade étnica, trabalho e economia). Esses últimos, sem se constituírem novas disciplinas, viriam informar o conjunto das disciplinas existentes e enriquecê-las, de vez que nelas se manifestam. São temas desafiadores trazidos pelo mundo contemporâneo e cujo impacto a escola, sobretudo na formação inicial e continuada de professores e professoras, não pode deixar de conhecer, reconhecer sua importância e deles se apropriar.

Os PCNs desencadearam um dos debates mais envolventes já vistos, entre especialistas, governantes, professores e demais interessados no assunto. Os pontos centrais desse debate envolveram de maneira especial o processo de elaboração da proposta e vários aspectos de seu produto tanto no âmbito de sua fundamentação geral, quanto no referente às áreas específicas.

Uma vez apresentados formalmente ao CNE e encaminhados à Câmara de Educação Básica, essa última deteve-se de modo analítico sobre os PCNs, a fim de verificar os limites e as possibilidades de atuação sob a competência desse colegiado. Anteriormente, o próprio CNE, por intermédio da Câmara de Educação Básica, tinha buscado compreender melhor tais limites e possibilidades por meio de Seminários Regionais sobre Parâmetros Curriculares Nacionais realizados em Recife, Cuiabá, São Paulo e Belém, visando a um contato mais específico com os Conselhos Estaduais e Municipais de Educação e com as instituições secundárias e universitárias responsáveis pela formação de profissionais do ensino.

Após todo este processo, a Câmara de Educação Básica exarou seu parecer sobre os Parâmetros Curriculares Nacionais em 12/3/97.

Em que pesem a importância dos PCNs e a legítima função do executivo federal em propô-los como decorrentes de um programa de governo, ainda que sem obrigatoriedade, a Câmara de Educação Básica, depois de amadurecida reflexão em torno de competências estabelecidas e à luz dos dispositivos constitucionais e infracons- 
titucionais existentes, entende que sua função deliberativa se volta para as diretrizes, que devem fundamentar a fixação de conteúdos minimos para o ensino fundamental, assim como para qualquer proposta curricular, nos diferentes níveis possíveis: estaduais, municipais e os cabíveis às unidades escolares.

A fim de justificar as distintas competências cabíveis às instâncias constituintes da federação cumpre entender o sentido da expressão diretrizes.

Diretrizes são linhas gerais que, assumidas como dimensões normativas, tornam-se reguladoras de um caminho consensual, conquanto não fechado a que historicamente possa vir a ter um outro percurso alternativo, para se atingir uma finalidade maior. Nascidas do dissenso, unificadas pelo diálogo, elas não são uniformes, não são toda a verdade, podem ser traduzidas em diferentes programas de ensino e, como toda e qualquer realidade, não são uma forma acabada de ser.

O termo diretriz significa caminhos propostos para e, contrariamente à imposição de caminhos, ele denota um conjunto de indicações pelo qual os conflitos se resolvem pelo diálogo e pelo convencimento. A diretriz supõe, no caso, uma concepção de sociedade e uma interlocução madura e responsável entre vários sujeitos, sejam eles parceiros, sejam eles, no campo político, dirigentes e dirigidos. Dessa interlocução, espera-se o traçado de diferentes modos de se caminhar para a efetivação dos fins comuns, obedecendo-se à diversidade de circunstâncias socioculturais, ao respeito aos valores culturais e artísticos, nacionais e regionais (cf. art. 210) e à recusa ao monopólio da verdade.

Os estudiosos da educação brasileira sabem muito bem o quanto este termo - diretriz - já significou de discussão e debate em relação à sua hermenêutica, quanto às suas dimensôes sociais, nacionais e jurídicas.

Embora a tradição política brasileira tenha sido dominantemente a do revestimento de diretrizes por estruturas cartoriais, clientelísticas ou autoritárias, na essência desta expressão prevalece o sentido de um rumo, de uma direção, de um caminho tendente a um fim. A celebração do Estado Democrático de Direito, com ênfase após 1988, supõe a crítica ao Estado Autoritário e suas seqüelas. Supõe também a busca de um caminho em que a cidadania seja reconhecida como tal e expressa em múltiplas e várias arenas de discussão e de decisão, próprias do Estado Democrático de Direito 
e de um Estado Federativo. Logo, à formulação de diretrizes à luz desse conceito, opõem-se tanto a imposição autoritária (que seria a absolutização de $u m$ fim tornado $o$ fim), quanto a dispersividade de orientações localistas e o espalhamento de detalhes e minúcias (que, por sua vez, seria a ausência de fins comuns).

Diretriz, assim, aproxima-se de orientação que é, ao mesmo tempo, impulso inicial e rumo geral. Mas aproxima-se também de norte, seja no sentido de superar uma possível desorientação, seja no sentido largo de orientação para um fim.

Esse sentido está presente no art. 90, IV, da Lei de Diretrizes e Bases da Educação Nacional, que assinala ser incumbência da União:

(...) estabelecer, em colaboração com os Estados, Distrito Federal e os Municípios, competências e diretrizes para a educação infantil, o ensino fundamental e o ensino médio, que nortearão os currículos e os seus conteúdos mínimos, de modo a assegurar a formação básica comum. (Grifos nossos)

Logo, os currículos e seus conteúdos mínimos (art. 210 da CF/ 88) propostos pelo MEC (art. 9o, letra c, da Lei no 9.131/95) terão seu norte estabelecido por meio de diretrizes. Estas terão como foro de deliberação a Câmara de Educação Básica (art. 9º, letra c, da Lei $\mathrm{n}^{\circ}$ 9.131/95). E dentro da opção cooperativa que marcou o federalismo no Brasil após a Constituição de 1988, a propositura das diretrizes será feita em colaboração com os outros entes federativos (LDB, art. $\left.9^{\circ}, I V\right)$. Entretanto o objetivo dessas diretrizes já está dado: tratase da formação básica comum, assegurada a todos os estudantes.

Ora, a federação, calcada na noção de colaboração, supõe um trabalho conjunto no interior do qual os agentes públicos buscam, pelo consenso, pelo respeito aos campos específicos de atribuiçôes, tanto metas comuns como os meios mais adequados para a consecução das finalidades maiores da educação nacional. Esta noção implica, então, o despojamento de respostas e caminhos previamente prontos e fechados.

Vista esta lógica, reserva-se aos entes federativos e ao próprio estabelecimento escolar, de acordo com a Constituição Federal e a LDB, a tarefa que lhes compete em termos de um proposta curricular, fruto de um projeto pedagógico como síntese entre as diretrizes e a situação contextualizada do estabelecimento.

Esta competência foi preenchida por obra da discussão e aprovação das Diretrizes Curriculares Nacionais da Educação Infan- 
til, do Ensino Fundamental, do Ensino Médio, do Ensino Normal Médio, da Educação dos Jovens e Adultos, das Comunidades Indígenas, dos Portadores de Necessidades Especiais, do Campo, da Educação Profissional, Nível Técnico.

A apropriação das Diretrizes pelos projetos pedagógicos permite o exercício da autonomia dos estabelecimentos no sentido de adequá-las à sua realidade.

Dada a nova legislação e a normatização que lhe é conseqüente, percebe-se que está extinta a noção de "currículo mínimo" nacionalmente fixado. Os entes federativos, assim, gozam de autonomia para enriquecer essas diretrizes com seus parâmetros.

Posta esta consideração sobre a pendência entre Diretrizes e Parâmetros, não se pode deixar de articular a questão dos componentes curriculares com a avaliação.

O papel da União em matéria de avaliação escolar não decorre de um ato arbitrário do governo. Ele está ancorado em lei. Basta verificar o art. $9^{\circ}$, VI, da LDB dentro de um sistema nacional de avaliação, segundo o art. $4^{\circ}$ do PNE e o art. $87, \$ 3^{\circ}$, IV, da LDB.

Mas se a avaliação é competência própria da União, ela o é também sob o regime de colaboração recíproca.

Assim, ao SAEB foi dada uma configuração diferenciada e também foi criado o Exame Nacional do Ensino Médio. O ENEM é um exame não-obrigatório, de vez que essa etapa da educação básica não conta com o caráter de obrigatoriedade. Ele pretende medir a aprendizagem dos alunos, podendo servir aos processos seletivos para ingresso nos cursos superiores ou no mundo do trabalho. Amparado na avaliação das respostas a itens que buscam medir competências e habilidades, o ENEM vem se tornando um dos principais programas de políticas educacionais da União com vistas, inclusive, a ser um componente determinante do processo seletivo para o ensino superior.

O Exame Nacional de Cursos (Provão) faz parte desta mesma lógica.

O problema é se a cooperação recíproca entre os sistemas, legalmente exigida para efeito de levar adiante o eixo da avaliação, está sendo efetivada tanto na montagem do processo avaliativo quanto na sua metodologia. Caso contrário, corre-se o risco de tornar os programas de avaliação novos paradigmas curriculares (do tipo currículo mínimo), inviabilizando a flexibilidade que a desburocra- 
tização legal permitiu em face da autonomia dos estabelecimentos escolares e refreando a criatividade estimulada pela lei. Nesse caso, a cooperação exigida em lei pode se transformar em formas sofisticadas de políticas centralizadoras.

O que se pode perceber, nestes dois mandatos do presidente Fernando Henrique Cardoso, é a intensa e diversificada obra de mudanças no âmbito da educação escolar. Essas mudanças se caracterizam por políticas focalizadoras, com especial atenção ao ensino fundamental, a fim de selecionar e destinar os recursos para metas e objetivos considerados urgentes e necessários. Tais políticas vieram justificadas por um sentido, por vezes pouco satisfatório, do princípio da eqüidade como se este fosse substituto do da igualdade.

Não há saída para as políticas da educação básica sem um horizonte universalista próprio do princípio da igualdade.

Se as políticas de descentralização sempre fizeram parte de nossa tradição histórica, pelo menos desde o Ato Adicional de 1834, agora elas adquiriram um caráter bem mais marcante na medida em que a Constituição de 1988 elevou os municípios à categoria de entes federativos. $\mathrm{Na}$ ausência de um sentido explícito e conseqüente do pacto federativo por cooperação recíproca, até por omissão do Congresso Nacional, a descentralização, nas mãos de um governo central poderoso, ganha um sentido de centralização de concepção e descentralização da execução nos níveis subnacionais de governo.

A rigor, as políticas de descentralização, sobretudo se acompanhadas do atual modo vigente do pacto federativo, significam um repasse de responsabilidade dos escalôes nacionais para os subnacionais. Se estes últimos não forem capazes de sustentar suas responsabilidades, o risco é o de haver um deslocamento do público para o privado e aí reside o risco maior de uma competitividade e seletividade, de corte mercadológicas, pouco naturais aos fins da educação.

No âmbito da educação básica, é bastante delicado falar em política de privatização dados os "amortecedores" do financiamento vinculado e do princípio da gratuidade associados ao "direito do cidadão e dever do Estado". Pelo menos até agora, o Brasil não conhece programas de "vouchers" ou vales, como é o caso do Chile, por exemplo. Contudo, o repasse de responsabilidades entre os escalóes de poderes públicos sem o devido sustentáculo financeiro acaba por significar a redução na capacidade de atendimento da demanda. No âmbito da educação básica, há sérios comprometi- 
mentos no interior da educação infantil e da educação de jovens e adultos. Esses comprometimentos conduzem a que os espaços que deveriam ser ocupados, por dever, pelo Poder Público, tornem-se apropriados pelo setor privado, especialmente por meio de parcerias, convênios ou terceirizações.

Um outro ponto importante a ser considerado é a política de desregulamentação. Nesse caso, as escolas, especificamente, foram aliviadas das múltiplas exigências cartoriais e burocráticas que cerceavam a autonomia dessas escolas. Entretanto, tal política depende de uma realização suficiente da política de financiamento. E esta remete tanto ao bom gerenciamento dos recursos vinculados como ao volume de recursos diante da capacidade de atendimento. Nesse último caso, não se pode deixar de apontar como obstáculo ao horizonte universalista, próprio dos direitos sociais, a sistemática recusa dos setores específicos da política econômica, referendada pela Presidência da República por meio dos vetos, em incluir a modalidade da educação de jovens e adultos no fundef e de ampliar (gradualmente) os recursos para a educação como um todo.

Em contrapartida, a visualização do status da educação tornouse mais clara com a rapidez e a organização das estatísticas educacionais levadas adiante pelo INEP. O INEP vem se ocupando dos programas de avaliaçãao e de certificação de competências. $\mathrm{O}$ problema todo continua sendo em torno da operacionalização do princípio da cooperação recíproca entre os entes federados.

As perspectivas de um maior cuidado com os aspectos lacunosos da nossa educação básica são preocupantes, pelo menos a curto prazo.

O primeiro elemento a se considerar, já fartamente denunciado, é a descontinuidade administrativa, expressa nas falas de ocupantes dos órgãos executivos da educação escolar, quando da rotatividade de ocupantes de cargos públicos. Não é de hoje que o passado é tido como a causa de todos os males, especialmente o passado próximo. O presente, idealizado como ponto inicial de uma nova realidade, torna-se o patamar decisivo da construção do futuro. O futuro, presentificado no presente, é o momento da superação e com isso se começa o absolutamente novo.

Estes discursos necessitam ser repensados a fim de não cairmos na noite em que todos os gatos são pardos. É necessário saber distinguir entre o que deve ser aperfeiçoado do que deve ser extinto, o que deve ou pode ser mantido do que deve ser transformado. 
Além do mais, tais discursos, por vezes, defrontam-se com realidades penosas como maiorias parlamentares adversas ou conflituosas com novas metas, pois determinadas mudanças supõem alterações constitucionais ou legais.

O segundo elemento a ser levado em conta é o $₫$ único do art. 23 da CF/88, que exige a elaboração de uma lei complementar que defina o que é um regime de colaboração recíproca entre os entes federados. Desde 1988, esse $₫$ único não foi levado adiante pelo Congresso Nacional. Sem essa definiç̧ão, o avançado e conceituado regime de colaboração de nossa Lei Maior, em seu modus operandi, vem se revelando muito mais um regime de decisōes nacionalmente centralizadas e de execuçóes de políticas sociais subnacionalmente desconcentradas em que se percebe uma situação de competitividade recíproca (guerra fiscal) entre os subnacionais.

Esta política de desconcentração de execuções, aliada a um centralismo decisório, associada à capacidade economicamente diferenciada dos governos subnacionais e à política advinda da Lei de Responsabilidade Fiscal (LRF), tem trazido tensōes problemáticas no âmbito do pacto federativo.

Muitas das políticas públicas de educação básica dependem do reordenamento do pacto federativo, apesar da vinculação orçamentária e constitucional da educação e sua gratuidade. Aqui, o palco de pressão é o Congresso Nacional, sabendo-se que esta definição do regime de cooperação conduz a questões candentes como papel da União, reforma tributária, política de criação de municípios e até mesmo revisão de atribuições e competências.

A educação básica - como competência dos poderes públicos -, em face da capacidade financeira e da capacidade de atendimento da demanda e da realização da educação como direito social, implica a responsabilização conjunta da União, dos estados e dos municípios. Neste sentido, o FUNDEF merece uma análise cuidadosa e fundamentada para que a proposta de um FUNDEB seja consistente, não sem antes verificar os passos exitosos ou problemáticos do modus operandi do próprio FUNDEF.

O terceiro elemento a ser relevado é a política nacional da economia. Todos nós somos favoráveis a mudanças que agreguem crescimento econômico, redistribuição de renda e estabilidade monetária. O problema está na conjugação simultânea destes aspectos numa situação de alta expectativa de mudança e de profunda herança de adverso 
constrangimento econômico-financeiro. Como fazê-lo, eis uma questão difícil, desafiadora e certamente não se fará da noite para o dia.

A política centrada em superávits primários faz o Estado Nacional recuar nos aspectos relativos aos direitos sociais, inclusive na obrigação de a União ser um pólo coordenador de política social por meio da função normativa, redistributiva e supletiva em relação às demais instâncias educacionais, segundo o $\$$ primeiro do art. $8^{\circ}$ da LDB. Afinal, como assegurar, de modo consistente, o aumento do gasto público sem uma previsão das fontes seguras de recursos?

A atual política de alto endividamento externo, associada à vulnerabilidade de nossas contas externas condiciona o jogo das contas públicas, o pacto federativo e impõe limites à soberania nacional. $\mathrm{E}$ isso condiciona os problemas e as perspectivas no âmbito educacional. Não se pode ignorar que nosso endividamento é soturno e maiores financiamentos provindos de fontes externas só fazem aumentá-lo. Ao mesmo tempo ele tem sido um fator importante da atual política, cujas conseqüências não se pode ignorar.

Por outro lado, sem uma redefinição dos encargos e das bases dos mesmos no pacto federativo, sem crescimento econômico, sem um forte mercado interno, sem uma revisão tributária interna, sem o enfrentamento do endividamento interno do setor público, a possibilidade de uma alteração de rumos fica quase que restrita ao combate à sonegação e à redefinição otimizada dos valores vinculados constitucionalmente à educação.

Como conjugar estas dimensões já que, de pronto, não é possível ter todas as coisas desejáveis ao mesmo tempo?

Certamente, um passo importante será dado se formos capazes de efetivarmos as metas e os objetivos do atual Plano Nacional de Educação, inclusive com a derrubada dos vetos.

O passo fundamental, porém, é a consciência da importância da educação básica por parte dos cidadãos. Essa consciência vem crescendo, de um lado, por causa transformação da base econômica de produção. E quando isso acontece, ela altera, mais ou menos rapidamente, toda a imensa superestrutura. Ao considerar tais alterações é necessário sempre distinguir entre a alteração material - que se pode comprovar de maneira cientificamente rigorosa - das condiçôes econômicas de produção e as formas jurídicas, politicas, religiosas, artísticas ou filosóficas, em resumo, as formas ideológicas pelas quais os homens tomam consciência deste conflito... (Marx, 1983, p. 25). E no tomar consciência 
deste conflito os cidadãos brasileiros começam a perceber a insuficiência dos chamados "padrōes mínimos" disto ou daquilo. O padrão mínimo é um limite entre o caráter humano da vida e de suas condições e o terreno da animalidade. A recuperação da liberdade humana, capaz de fazer opçóes, e o avanço pela igualdade, patamar maior da cidadania, são hoje aspirações que fluem das várias camadas sociais, especialmente das que foram excluídas da participação dos bens sociais.

Quanto mais amadurecidas forem nossas propostas e seriamente discutidas, menores serão nossas ilusões e maiores as perspectivas de ir traçando um horizonte mais promissor para a democratização e universalização da educação básica.

Recebido e aprovado em julho de 2002.

Referências bibliográficas

ALMEIDA, F.D.M. Competências na Constituição de 1988. São Paulo: Atlas, 1991.

MARX, K. Prefácio à Contribuição à crítica da economia política. São Paulo: Martins Fontes, 1983. 